\title{
Maternofetal outcome in obstructed labour in a tertiary care hospital
}

\author{
Syed Masuma Rizvi ${ }^{1}$, Nikita Gandotra ${ }^{2 *}$
}

\author{
${ }^{1}$ Associate Professor, ${ }^{2}$ Resident, Department of Obstetrics \& Gynaecology, Government Medical College, Srinagar, \\ Jammu and Kashmir, India
}

Received: 01 August 2015

Accepted: 17 August 2015

\author{
*Correspondence: \\ Dr. Nikita Gandotra \\ E-mail: nikigandotra@gmail.com
}

Copyright: (c) the author(s), publisher and licensee Medip Academy. This is an open-access article distributed under the terms of the Creative Commons Attribution Non-Commercial License, which permits unrestricted non-commercial use, distribution, and reproduction in any medium, provided the original work is properly cited.

\begin{abstract}
Background: Obstructed labour is still a major cause of maternal morbidity and mortality and adverse outcome of newborn in low income countries. It is the leading cause of hospitalization, comprising of $39 \%$ of all obstetric patients in developing countries. Objectives: To study frequency, causes outcome and complications of obstructed labour.

Methods: 402 patients admitted with feature of obstructed labour were studied. Detailed history included sociodemographic factors, obstetric history, features of obstruction, intrapartum events were recorded. Condition of patients, mode of delivery, preoperative and postoperative complications, maternal and fetal outcomes was recorded.

Results: A total of 23381 deliveries were conducted during one year, 402 cases of obstructed labour were found with incidence of $1.71 \% .86 .5 \%$ of the patients were from rural areas and $78.1 \%$ of patients were unbooked and $73.3 \%$ patients were primigravida. The commonest cause of obstructed labour was cephalopelvic disproportion (55\%) followed by Malposition (22.9\%) and Malpresentation (17.9\%). The commonest mode of delivery was cesarean section $(83.8 \%)$. Instrumental deliveries were conducted in $10.5 \%$ of cases. Destructive procedures are discouraged in out set up. Rupture uterus was seen in 16 cases (4.16\%) out of which repair was done in 11 cases and subtotal hysterectomy was performed in 5 patients. The common maternal complications were sepsis [pyrexia (15.1\%), wound infections (12.8\%), urinary tract infection (7\%), abdominal distention (11.2\%), postpartum hemorrhage $(9.7 \%)$. Perinatal mortality was $107 / 402(26.6 \%)$, live birth rate $316 / 402(78.7 \%)$, still birth rate $86 / 402(21.3 \%)$. Perinatal morbidity was most commonly due to birth asphyxia (28.8\%), jaundice (16.9\%), septicemia (14.75\%), meconium aspiration syndrome $(9.9 \%)$.

Conclusions: Obstructed labour is a preventable condition prevalent in developing countries. Improving nutrition, antenatal care, early diagnosis and timely intervention may result in decrease in incidence of morbidity and mortality.
\end{abstract}

Keywords: Obstructed labour, Cephalopelvic disproportion, Perinatal mortality

\section{INTRODUCTION}

Labour is considered obstructed labour when the presenting part of the foetus cannot progress into the birth canal, despite strong uterine contractions which leads to various maternal or foetal complications. ${ }^{1}$ Obstructed labour accounts for about $8 \%$ of all maternal deaths in developing countries like India. ${ }^{2}$ It is a leading cause of hospitalization, comprising up to $39 \%$ of all obstetric patients in developing countries. ${ }^{3}$ Obstructed labour is the single most important cause of maternal death and is one of the leading causes of perinatal mortality. ${ }^{4}$ Maternal mortality ranges between $1 \%$ and $13 \%$ and perinatal mortality between $74 \%$ and $92 \%{ }^{5,6}$ It is one of the most common preventable causes of maternal morbidity and mortality in developing countries.

Each year, 210 million women become pregnant of whom 20 million will experience pregnancy related illness and 500,000 will die as a result of complications 
of pregnancy or childbirth. ${ }^{7}$ In 1987, the World Health Organization launched the Safe Motherhood Initiative, which aimed to reduce maternal morbidity and mortality by $50 \%$ by year 2000 .This initiative did not succeed, but maternal health continues to be a major focus of WHO effort. The current WHO initiative ${ }^{8}$ is to reduce maternal mortality to $75 \%$ of 1990 level by 2015 . If this is to be successful, the problem of obstructed labour will need to be addressed effectively.

Maternal mortality from obstructed labour is largely the result of ruptured uterus or puerperal infection, whereas perinatal mortality is mainly due to asphyxia. Significant maternal morbidity is associated with prolonged labour, since both postpartum haemorrhage and infection are more common in women with prolong labour. Obstetric fistulas are long term problems. Traumatic delivery affects both mother and child. ${ }^{7,8}$

There are differences in the behaviour of the uterus during obstructed labour, depending upon whether the women has delivered previously. The pattern in primigravida women (typically diminishing contractility with risk of infection and fistula) may result from tissue necrosis whereas in parous women, contractility may be maintained with risk of uterine rupture. ${ }^{9}$

The present study was conducted to detect the risk factors, presentation, management and outcome of obstructed labour in a tertiary care centre, so that early intervention strategies may decrease the incidence of morbidity and mortality.

Objectives: To study the frequency, causes, management, outcome and complications of obstructed labour. This will help to formulate a positive strategy in our setup to prevent obstructed labour and its consequence.

\section{METHODS}

This prospective study of obstructed labour was conducted from May 2014 to May 2015 in the Department of obstetrics and Gynaecology of Government Medical College Srinagar, which is the only tertiary obstetric care hospital in the Kashmir valley where cases are referred to not only from peripheral hospitals and rural areas but also from local general practitioners. All patients admitted with obstructed labour were included in the study.

Detailed history regarding age, socioeconomic status, parity, previous obstetric history, past history, antenatal care, duration of labour, details of referral and management were recorded. During admission, the general condition of mother was assessed as well as fetal lie, presentation, position and heart sounds were recorded. Pelvic examination was carried out to assess the cervical dilatation, state of liquor amniii, position, pelvic assessment, degree of caput, moulding.
Diagnosis of maternal exhaustion, dehydration, genital sepsis, pyrexia, rupture uterus, post-partum hemorrhage, Vesico-vaginal fistula, and shock was made. Any death occurring as a consequence of obstructed labour was noted. Diagnosis of live or asphyxiated or dead fetus or neonatal death was done by taking APGAR score at 1 and 5 minutes following birth. Mode of delivery (Assisted vaginal, cesarean section), time interval between referrals, admission, intervention done at tertiary care centre and related fetomaternal outcome were noted. Destructive procedures are discouraged in our centre. At postpartum period, data regarding maternal outcome were recorded which included abdominal distension, postpartum hemorrhage, foul smelling discharge, fever, character of wound, burning micturation, urinary incontinence. Fetal condition was evaluated by the nature of feeding, development of jaundice, neonatal infections. Outcome and complications of Lower segment Cesarean Section (LSCS), instrumental deliveries (vacuum extraction, forceps) were recorded.

\section{RESULTS}

During the one year study period, there were total of 23381 deliveries of which 402 cases were diagnosed to have obstructed labour, incidence being $1.71 \%$.

Table 1: Magnitude of obstructed labour.

\begin{tabular}{|lll|}
\hline Total deliveries & Obstructed labour & $\%$ \\
23381 & 402 & 1.71 \\
\hline
\end{tabular}

Table 2: Demographic profile.

\begin{tabular}{|lll|}
\hline Characteristics & Number & $\%$ \\
\hline Residence & & \\
\hline Rural & 348 & 86.5 \\
\hline Urban & 54 & 13.43 \\
\hline Antenatal Checkup & & \\
\hline Booked & 88 & 21.9 \\
\hline Unbooked & 314 & 78.1 \\
\hline
\end{tabular}

Maximum cases were in age group of 19-24 years $(64.4 \%) .86 .5 \%$ of the patients were from rural areas and $78.2 \%$ of the patients were unbooked. The commonest cause of obstructed labour was cephalopelvic disproportion (55\%). Other causes were Malposition (22.9\%), Malpresentation (17.9\%), foetal congenital abnormality $(1.38 \%)$, Myomas $(0.83 \%)$, others $(0.83 \%)$. $4(1.11 \%)$ cases of previous caesarean section came in advanced stage of obstructed labour and resulted in rupture uterus.

Table 3: Age distribution of patients.

\begin{tabular}{|lll|}
\hline Age (Years) & Number & $\%$ \\
\hline $19-24$ & 261 & 64.9 \\
\hline $25-29$ & 98 & 24.3 \\
\hline$>30$ & 43 & 10.69 \\
\hline
\end{tabular}


The commonest mode of delivery was caesarean section (83.8\%). Instrumental deliveries were performed in $10.5 \%$ of cases. Rupture cases was present in 16 cases out of which repair was done in 11 cases and hysterectomy was done in 5 cases. The most common maternal complications were sepsis (pyrexia $(15.1 \%)$, urinary tract infection (7\%), wound infections (12.8\%), abdominal distention $(11.2 \%)$, post-partum haemorrhage (PPH) $(9.7 \%)$.

Table 4: Parity of patients of obstructed labour.

\begin{tabular}{|lll|}
\hline Parity & Number & $\%$ \\
\hline Primigravida & 295 & 73.3 \\
\hline Multigravida $(<3)$ & 63 & 15.67 \\
\hline Grandmultigravida(>3) & 44 & 10.94 \\
\hline
\end{tabular}

Table 5: Causes of obstructed labour.

\begin{tabular}{|lll|}
\hline Causes & Number & $\%$ \\
\hline Cephalopelvic disproportion & 221 & 55 \\
\hline Malposition & 92 & 22.9 \\
\hline Malpresentation & 73 & 17.9 \\
\hline Fetal congenital anomaly & 6 & 1.38 \\
\hline Myoma & 3 & 0.83 \\
\hline Previous cesarean section & 4 & 1.11 \\
\hline Others (non-dilation of cervix) & 3 & 0.83 \\
\hline
\end{tabular}

Table 6: Different modes of delivery.

\begin{tabular}{|lll|}
\hline Type & Number & $\%$ \\
\hline Cesarean section & 337 & 83.8 \\
\hline Instrumental delivery & 42 & 10.5 \\
\hline $\begin{array}{l}\text { Laparotomy with repair of rupture } \\
\text { uterus }\end{array}$ & 11 & 3.05 \\
\hline Subtotal hysterectomy & 12 & 2.5 \\
\hline
\end{tabular}

Table 7: Maternal complications of obstructed labour.

\begin{tabular}{|c|c|c|}
\hline Complication & Number & $\%$ \\
\hline \multicolumn{3}{|l|}{ Maternal Sepsis } \\
\hline Pyrexia & 61 & 15.1 \\
\hline $\begin{array}{l}\text { Urinary Tract } \\
\text { Infection }\end{array}$ & 28 & 7 \\
\hline Wound Infection & 51 & 12.8 \\
\hline Postpartum Hemorrhage & 39 & 9.7 \\
\hline Rupture Uterus & 16 & 4.16 \\
\hline Vesico Vaginal Fistula & 6 & 1.11 \\
\hline Bladder Injury & 6 & 1.11 \\
\hline Hysterectomy & 12 & 2.9 \\
\hline Maternal Death & 3 & 0.74 \\
\hline Broad Ligament Hematoma & 3 & 0.83 \\
\hline Abdominal Distention & 46 & 11.2 \\
\hline Peritonitis & 5 & 1.38 \\
\hline Subinvolution & 40 & 10 \\
\hline No Complications & 86 & 21.3 \\
\hline
\end{tabular}

Other complications were Rupture uterus (4.16\%); vesicovaginalfistula $(1.11 \%)$, bladder injury $(1.1 \%)$, hysterectomy $(2.5 \%)$, broad ligament hematoma $(0.83 \%)$, and sub involution (10\%). There were 5 maternal deaths due to complications associated with obstructed labour. Total live births were $568(78.8 \%)$ and $152(21.2 \%)$ were still births. Perinatal complications included birth asphyxia (28.8\%), jaundice (16.9\%), and septicaemia $(14.5 \%)$, meconium aspiration syndrome $(9.9 \%)$. There were total 183 perinatal deaths maximum being due to birth asphyxia (TABLES 1-9).

Table 8: Fetal outcome of obstructed labour.

\begin{tabular}{|lll|}
\hline Outcome & Number & $\%$ \\
\hline Live Births & 316 & 78.7 \\
\hline Still Births & 86 & 21.3 \\
\hline
\end{tabular}

Table 9: Perinatal complications of obstructed labour.

\begin{tabular}{|lll|}
\hline Morbidity & Number & $\%$ \\
\hline Birth Asphyxia & 91 & 28.8 \\
\hline Septicemia & 46 & 14.7 \\
\hline Meconium Aspiration Syndrome & 31 & 9.9 \\
\hline Convulsions & 8 & 3.8 \\
\hline Jaundice & 53 & 16.9 \\
\hline Umbilical Sepsis & 11 & 3.6 \\
\hline No Complications & 76 & 23.5 \\
\hline
\end{tabular}

\section{DISCUSSION}

The incidence of obstructed labour in the present study was $1.71 \%$ which was lower than the incidence by Fantu et $\mathrm{al}^{10}(12.2 \%), 4.2 \%$ by Islam et al, ${ }^{11} 2.7 \%$ by Ikojo et $\mathrm{al}^{12} 3.3 \%$ by Gassessew et $\mathrm{al}^{13} 2.1 \%$ by Menon et al, $3.2 \%$ by Aboyeji et al. ${ }^{14}$ It was higher than the incidence by Sabyasachi et al ${ }^{15} 1.64 \%, 1.1 \%$ by Ritu et al, ${ }^{16} 0.56 \%$ reported by Adhikari et al, ${ }^{17} 0.8 \%$ by Omele-ohonsi et al, ${ }^{18} 1.27 \%$ by Dafallah et al. ${ }^{19}$ The decreasing trend is a reflection of improvement in antenatal and intranatal care.

In our study, common causes of obstructed labour were cephalopelvic disproportion (55\%), Malposition (22.9\%), Malpresentation (17.9\%). Mostly the patients were primigravida $(73.3 \%)$ and of age group 19-24 years $(64.9 \%)$. The incidence of obstructed labour was higher in unbooked patients (78.1) comparable to study done by Shimelis and Fantu et al. ${ }^{10} 86.5 \%$ of the patients who presented with features of obstruction were from rural areas showing lack of proper healthcare facilities.

Lower segment cesarean section was the commonest method of delivery ( $83.8 \%)$, followed by instrumental deliveries $(10.5 \%)$. In our center destructive procedures are not encouraged. There were total 16 cases of rupture uterus out of which 11 were repaired and 7 underwent subtotal hysterectomy. 
Maternal mortality in the study group was 3/402 (0.74\%), lower than study by Sabyasachi et $(1.60 \%)$, Adhikari et $\mathrm{al}^{17}(2.04 \%)$, Nwogu-ikojo ${ }^{12}$ et al $(3.3 \%)$ showing the timely management of the patient in our set up. In our study common maternal complications were maternal sepsis (pyrexia (15.1\%), urinary tract infection $(7 \%)$, wound infection (12.8\%) total (34.9\%), abdominal distention (11.2\%), Post-partum hemorrhage (9.7\%), sub involution $(10 \%)$, rupture uterus $(4.16 \%)$. Vesico vaginal fistula was noted in 6 patients $(1.49 \%)$.

The total number of live births were $316(78.7 \%)$ and still birth $86(21.3 \%)$. Perinatal mortality reported from various studies was as follows: Dafallah et $\mathrm{al}^{18} 27.1 \%$, Neena et $\mathrm{al}^{19} 38 \%$, Sabyasachi ${ }^{15}$ et al $22.68 \%$. In our study perinatal mortality was $107 / 401$ (26.6\%). Perinatal morbidity was commonly dye to birth asphyxia (28.8\%), Jaundice (16.9\%), Septicemia (14.7\%), Meconium aspiration syndrome $(9.9 \%)$.

\section{CONCLUSIONS}

Obstructed labour continues to be a major cause of maternal and perinatal morbidity in low income countries and accounts for approximately $8 \%$ of maternal deaths globally. The common mode of delivery is by caesarean section. Poor referral system, low socioeconomic status, inadequate antenatal care services lead to many cases of obstructed labour. They are further compounded by poor road connectivity resulting in delayed specialized care. Lack of well quipped secondary and tertiary care centers that are adequately staffed is also an important factor for better obstetric care. Early recognition of obstructed labour cases and immediate safe abdominal or vaginal delivery can decrease the incidence of maternal and perinatal morbidity and mortality. Addressing socio demographic determinants will certainly contribute towards reducing the incidence of obstructed labour.

\section{Funding: No funding sources}

Conflict of interest: None declared

Ethical approval: The study was approved by the Institutional Ethics Committee

\section{REFERENCES}

1. Ammanuel Gessessew, Mengiste Mesfin. Obstructed labour in Adigrat Zonal Hospital, Tigray region, Ethiopia, Ethiop. Health Dev. 2003;17(3):175-80.

2. Cron J. Lessons from the developing world: Obstructed labor and the vesico-vaginal fistula. Med Gen Med. 2003;5:24.

3. Mekbib T, Kassaye E, Getachew A, Tadesse T, Debebe A. The FIGO save the Mothers Initiative:
The Ethiopia-Sweden collaboration. Int J Gynaecol Obstet. 2003;81:93-102.

4. Weeks A, Lavender T, Nazziwa E, Mirembe F. Personal accounts of 'near-miss' maternal mortalities in Kampala, Uganda. BJOG 2005;112:1302-7.

5. Rahman $\mathrm{MH}$, Akter $\mathrm{HH}$, Khan Choudhury ME, Yusuf HR, Rochat RW. Obstetric deaths in Bangladesh 1996-1997. Int J Gynaecol Obstet 2002; 77:161-9.

6. Hofmeyr GJ, Say L, Gülmezoglu AM. WHO systematic review of maternal mortality and morbidity: The prevalence of uterine rupture. BJOG 2005;112:1221-8.

7. McCarthy M. What's going on at the World Health Organization? Lancet 2002;360:1108-10.

8. McCarthy M. A brief history of the World Health Organization. Lancet 2002;360:1111-14.

9. Nelson JP, Lavinder T, S Quenby et al. obstructed labour, Reducing maternal death and disability during pregnancy. Br Med Bull. 2003;67(1):191-204.

10. Fantu S, Segni H, Alemseged F. Incidence, Causes and Outcome of Obstructed Labor in Jimma University Specialized Hospital. Ethiop J Health Sci. 2010; 20:145-51.

11. Islam JA, Ara G, Choudhary FR. Risk factors and outcome of obstructed labour at a tertiary care Hospital. J Shaheed Suhraeardy Med Coll. 2012;4(2):43-6.

12. Nwogu-Ikojo EE, Nweze SO, Ezegwui HU. Obstructed labour in Enugu, Nigeria. J Obstet Gynaecol. 2008;28:596-9.

13. Meiah GS, EL-Nafaty AU, Massa AA, Audu BM. Obstructed labour: A public health problem in Gombe, Gombe State, Nigeria. J Obstet Gynaecol. 2003;23:369-73.

14. Aboyeji AP, Fawole AA. Obstructed labour in Ilorin, Nigeria. A one year prospective study. Niger Med Pract. 1999;38:1-3.

15. Sabyasachi mondal, fetomaternal outcome of obstructed labour Med Jour DY PATIL. Vol6 issue 2 146-50.

16. Ritu Gupta Obstructed labour: Incidence, causes and outcome. Int J Bio Med Res. 2012;3(3):2185-8.

17. Adhikari S, Dasgupta M, Sanghamita M. Management of obstructed labour; A retrospective study. J Obstet Gynaecol India 2005;55:48-51.

18. Dafaiiah SE, Ambago J, El-Agib F. Obstructed labour in a teaching hospital in Sudan. Saudi Med J. 2003; 24:1102-4.

19. Chuni N. Obstructed labour in Eastern Nepal. Singapore J Obstet Gynecol. 2008;39:1-7.

Cite this article as: Rizvi SM, Gandotra N.

Maternofetal outcome in obstructed labour in a tertiary care hospital. Int J Reprod Contracept Obstet Gynecol 2015;4:1410-3. 